\title{
Damage Identification in Timber Structures Based on Wavelet Singular Spectrum Entropy
}

\author{
Shengcai Li $\mathbb{D}$, Lei Zhang $\mathbb{D}^{\mathbb{D}}$, Jie Tang, Daijian Ling, and Peixuan Wang \\ School of Architectural Science and Civil Engineering, Yangzhou University, 225127, China \\ Correspondence should be addressed to Lei Zhang; zhanglei_hebut@126.com
}

Received 28 July 2018; Revised 6 September 2018; Accepted 23 September 2018; Published 8 October 2018

Academic Editor: Lukasz Pieczonka

Copyright (C) 2018 Shengcai Li et al. This is an open access article distributed under the Creative Commons Attribution License, which permits unrestricted use, distribution, and reproduction in any medium, provided the original work is properly cited.

\begin{abstract}
Vibration responses of building structure closely related to the structural health status. In this paper, wavelet singular spectrum entropy (WSSE) is proposed to evaluate the damage condition of building structure. A 1/3 scaled model of a Chinese ancient timber structure has been constructed, and three damage conditions and one restored condition of the structure are simulated. The acceleration responses for undamaged and the four simulated damaged and restored conditions are measured and analyzed by employing WSSE to identify the location at which the structure has incurred damage. Results show that (1) the relative variation rate of WSSE for the damaged position changes significantly; (2) the relative variation rate of WSSE of the point that is damaged more severely would become higher; and (3) signals of North-South and East-West directions are required for further identification. Moreover, a finite element modeling analysis of the timber structure under different damage conditions is performed, and the results verify the applicability of the method proposed.
\end{abstract}

\section{Introduction}

Timber structural building is widely distributed in China. After a long service, a timber building might incur some damage and defects, which could considerably weaken the bearing capacity and reduce its structure's stability. Hence, it is of great importance to identify the location of damage and the degree of damage in a timber structure so that the structure could be evaluated and be well maintained and protected.

Identification of structural damage comprises local detection and global detection. The methods used for local detection comprise the ultrasonic pulse method and the $\mathrm{X}$ ray method, while global detection involves observing the specific changes in structural vibration to evaluate structural health [1]. The commonly used frequency domain or time domain identification methods cannot meet the requirements of local analysis in time and frequency domain simultaneously. Wavelet analysis decomposes the signal into the sum of mother wavelets or wavelet basis functions of different translation and scale factors, so that it has different window functions. Meanwhile, wavelet analysis has good local analysis function and can detect signal discontinuity and breakpoint. The local analysis of the signal can be implemented by wavelet analysis in any time or space domain [2]. Thus far, efforts have been devoted to the study of damage identification. Rucka and Wilde [3] analyze the damage location in a beam and a plate structures, respectively, by using one-dimensional Gaussian wavelet and two-dimensional reverse biorthogonal continuous wavelet transform. Hester and Gonzalez [4] use the energy of wavelet decomposed acceleration response to a moving load (vehicle) as a damage feature for structural health monitoring. The wavelet representation reveals that those damaged strips have a higher wavelet energy content than the undamaged strips.

The research on damage identification of wavelet analysis mainly focuses on high frequency wavelet transform coefficient, wavelet packet transform, wavelet basis function expansion, multiscale wavelet transforms, and wavelet singularity theory. Douka et al. [5] identifies the location and depth of cracks on a cantilever beam by using the continuous wavelet transform coefficient and the Lipschitz index of vibration mode. Yam et al. [6] effectively identify the location 
of damage in a composite laminated plate through a combination of wavelet packet, which disassembles the energy of the collected signals, and the neural network method. Wang and Deng [7] adopted multiscale wavelet transform to identify the location of cracks in a simply supported beam. As discussed by $\mathrm{Li}$ [8], wavelet analysis is adopted to perform damage analysis to provide an early warning for damage to ancient timber structures enduring random excitation and evaluated the relative changes between each frequency band by determining the energy ratio deviation and energy ratio variance, which are warning indices of the degree of damage in timber structures. Wang et al. [9] identified damage in a timber structural model by using acceleration response signals under environment excitation by using the wavelet packet energy curvature difference method, and although the feasibility of the method is verified theoretically, it has not yet been verified in practice.

Wavelet singular spectrum entropy (WSSE) can be used to indicate the uncertainty of vibration response signals in time-frequency energy distribution and measure and analyze the complexity and uncertainty of the fault transient signal so as to provide quantitative and intuitive analysis results for the research on failure. Li et al. [10] employed a damage diagnosis method based on singular spectral entropy and impulse response for a Benchmark structure proposed by the ASCE institute. Furthermore, the accuracy of the method is validated based on the identification of the location of damage. He et al. [11] perform a finite element analysis on a pile structure, by calculating the relative variation in the distribution of wavelet packet energy entropy bearing the impulse response, and the relative variation is used as a recognition feature parameter for identifying the location of damage and degree of damage of the pile structure. However, experimental verification is not performed for the pile structure.

According to research on damage identification based on the wavelet theory, the entropy method is seldom used in identifying damage in timber structures. Theoretical methods and simulated calculations are often used for damage localization; however, very few verification tests have been performed. In this study, a 1/3 scaled model of a timber structure named "Zhoufujiu" is constructed. Tests are performed on the model based on the WSSE theory, and the change in WSSE is used for damage localization and degree of damage. The effectiveness of this method for damage identification of timber structures is verified by a numerical analysis.

\section{Damage Identification Method Based WSSE Theory}

2.1. Wavelet Singular Value Decomposition. When a structure incurs damage, its vibration response will change. The change in structure vibration can reflect its current working state, and it can be used as an indicator for evaluating the state of a structure. The relative variation rate of WSSE is used to indicate the working state of the structure in this study.

Singular value decomposition of matrix is an important analytical method in signal processing, statistical analysis,

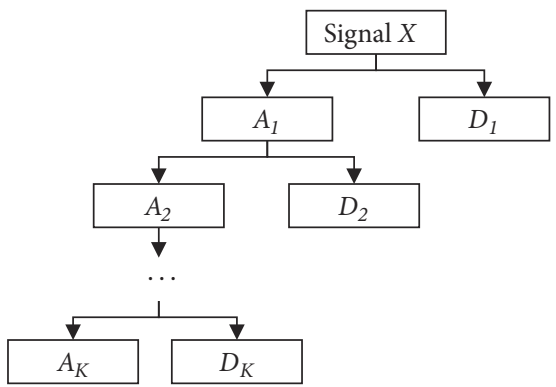

FIGURE 1: K layer decomposition structure of wavelet.

and optimization theory. For a test signal $X$ with length of $\mathrm{N}$,

$$
X=\left(x_{1}, x_{2}, \ldots x_{N-1}, x_{N}\right) .
$$

The appropriate wavelet transform function is selected and the signal $X$ is decomposed into $\mathrm{K}$ layers, and the details as well as the approximations can be split, which is shown in Figure 1 and (2), where, $A_{1}, \ldots, A_{k}$ are approximate values of 1-K level decomposition and $D_{1}, \ldots, D_{k}$ are details of 1 -K level decomposition. The coefficient matrix of decomposed signal $X$ is shown in (3).

By comparing several wavelet basis functions such as Morlet, Gaussian, Daubechies 2, Daubechies 5, and Mexicanhat, it is found that Daubechies 5 has the best sensitivity to singularity of signals [12], so Daubechies 5 is employed as wavelet basis function in this study. The measured signal is decomposed 9 times, as more decomposition data will not change obviously.

$$
\begin{aligned}
X & =A_{K}+D_{K}+\ldots+D_{2}+D_{1} \\
M_{N \times(K+1)} & =\left[\begin{array}{lllll}
D_{1} & D_{2} & \cdots & D_{K} & A_{K}
\end{array}\right] \\
& =\left[\begin{array}{llll}
d_{1,1} & \cdots & d_{K, 1} & a_{K, 1} \\
d_{1,2} & \cdots & d_{K, 2} & a_{K, 2} \\
\cdots & \cdots & \\
d_{1, N} & \cdots & d_{K, N} & a_{K, N}
\end{array}\right]
\end{aligned}
$$

where

$$
D_{i}=\left(\begin{array}{llll}
d_{i, 1} & d_{i, 2} & \ldots & d_{i, N}
\end{array}\right) \quad(i=1,2, \ldots, K) .
$$

This is the wavelet transform detail of the test signal $X$ on the $i$ th scale.

$$
A_{K}=\left(\begin{array}{llll}
a_{K, 1} & a_{K, 2} & \ldots & a_{K, N}
\end{array}\right)
$$

This is the approximate representation of the wavelet transform of the test signal $X$ on the $K$ th scale.

The coefficient matrix (3) is decomposed by singular value decomposition, and (6) is obtained.

$$
M_{N \times(K+1)}=U_{N \times N} \Lambda_{N \times(K+1)} V_{(K+1) \times(K+1)}
$$

where $U_{N \times N}$ and $V_{(K+1) \times(K+1)}$ are orthogonal matrices.

$$
\Lambda=\left[\begin{array}{l}
\Delta \\
0
\end{array}\right], \quad \Delta=\operatorname{diag}\left[\lambda_{1}, \lambda_{2}, \ldots \lambda_{K+1}\right]
$$


$\lambda_{1} \geq \lambda_{2} \geq \ldots \geq \lambda_{\mathrm{K}+1}$ are the singular values of the wavelet decomposition coefficient matrix $M_{N \times(K+1)}$ [2].

2.2. WSSE Theory. The wavelet singular value spectrum of test signal $X$ is recorded as vector:

$$
\text { Spectrum } X=\left\{\lambda_{1}, \lambda_{2}, \ldots, \lambda_{K+1}\right\} .
$$

The singular spectrum entropy is defined as follows:

$$
H=-\sum_{i=1}^{m} p_{i} \log p_{i}
$$

where $p_{i}$ is the proportion of the $i$ th mode of the whole mode.

$$
p_{i}=\frac{\lambda_{i}}{\sum_{i=1}^{m} \lambda_{i}}
$$

Singular spectrum entropy reflects the uncertainty of each mode under the singular spectrum division in the time domain signal and the time domain complexity of signal energy distribution. When the distribution of the signal energy tends to be simple, energy will be concentrated in a few modes, and the corresponding singular entropy value will be lower. In contrast, if the signal is more complex and the energy is more dispersed, then the value of the corresponding singular entropy will be higher. Therefore, singular spectrum entropy can describe the degree of complexity of the energy distribution of singular components in the signal.

\section{Experimental Study}

3.1. Test Introduction. In this study, a timber structure is taken as the research object. The height, width, and length of the structure are $2.94 \mathrm{~m}, 2.18 \mathrm{~m}$, and $3.65 \mathrm{~m}$, respectively, and the structure comprises two floors. The wooden frame is constructed with through-jointed frame method and beamlifted frame method. A $1 / 3$ scaled model of the structure is constructed for testing, as shown in Figure 1. The material used for constructing the model is fir wood. In particular, the columns are located in wooden boxes filled with wood blocks, instead of traditional bases, which is convenient for adjusting the settlement of column bases.

The measuring points are arranged on Column 1 and Column 2 at the bottom of the first floor, node of the second floor, and the top of the second floor, as shown in Figures 2 and 3. The acceleration response signals of the timber model under different conditions are collected and analyzed in the test. The values of WSSE under different conditions and their changes are obtained. Furthermore, the relationship between the relative variation rate of WSSE and the location of damage of the timber structure is investigated. Based on the results, we can evaluate the damage state of the structure.

3.2. Simulation of Different Conditions. Two columns are selected and damaged artificially to simulate the actual damage of the timber structure. Further, restored conditions are simulated to confirm the effectiveness of using relative variation rate for damage identification. Thus, the status of the model comprises five conditions, namely,

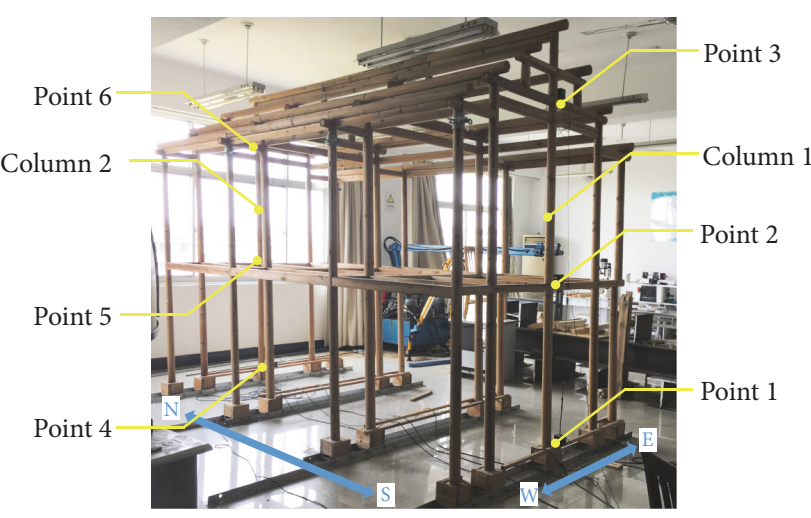

FIGURE 2: Undamaged timber structure model.

(i) Undamaged structure: the model is undamaged, as shown in Figure 2.

(ii) Damage condition 1: the bottom of Column 1 is completely corroded. To simulate this damage condition, the wooden blocks in the wooden box base of Column 1 are removed, and the column is in a suspended state, as shown in Figure 4.

(iii) Damage condition 2: the bottoms of both Column 1 and Column 2 are completely corroded. Similarly, the wooden blocks in the wooden base of the two columns are removed, and the columns are in a suspended state.

(iv) Damage condition 3: Column 1 is damaged. To simulate this condition, a semicylinder with $25 \mathrm{~cm}$ height is sawed underneath the joint of the second floor in Column 1, as shown in Figure 5.

(v) Restored condition: To confirm the effectiveness of using the relative variation rate for damage identification, the damaged Column 1 was repaired. The halfcylinder that was sawed from Column 1 was pasted to its original location by using wood adhesive. Then, wood shavings mixed with wood glue were used to fill in the gaps. Finally, the half-cylinder was fixed to the column by a small-gauge wire, as shown in Figure 6 .

3.3. Environmental Excitation Test. The response of the structure under environmental excitation is a random process, and the response will change accordingly when the structure is damaged. An environmental excitation test is carried out in this study, and the acceleration responses of the six measuring points in the North-South and East-West directions under each condition are measured, respectively. The acceleration response of the structure is obtained through smoothing and filtering.

3.4. Damage Identification Based on WSSE. According to the measured and processed acceleration signals, the values of the WSSE of the structure in the North-South and EastWest directions under each damaged condition are calculated based on the WSSE theory. If the WSSE value of the measured location is different from that of the corresponding position 


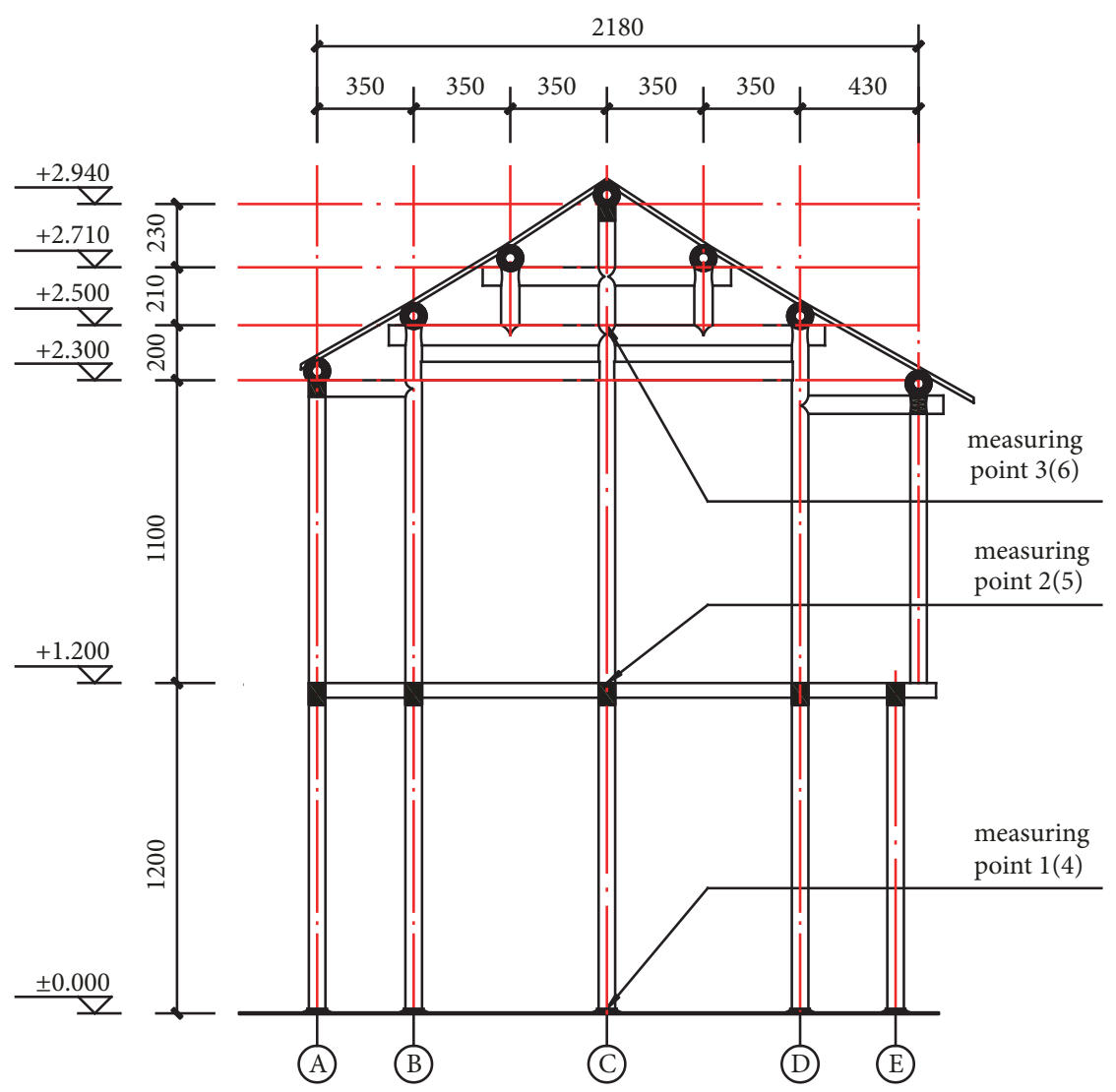

FIGURE 3: Measuring points of Column 1 and 2.

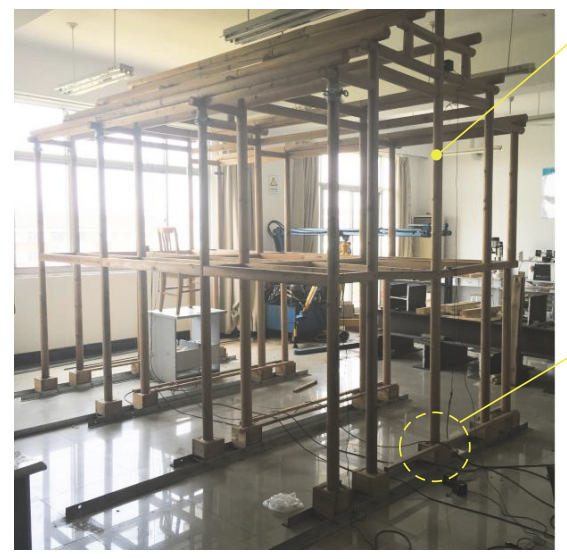

Column 1

Damaged position

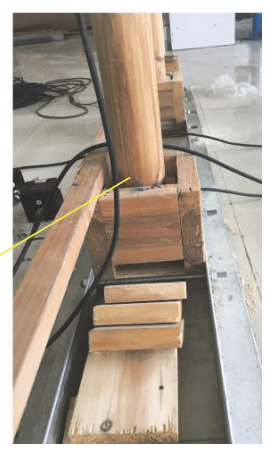

FIgURE 4: Damage condition 1 in which the bottom of Column 1 is simulated to be corroded completely.

of the intact structure, then it can be concluded that the structure is damaged at that location. The relative variation rate of entropy can be defined as follows:

$$
C R(t)=\frac{A(0)-A(t)}{A(0)}
$$

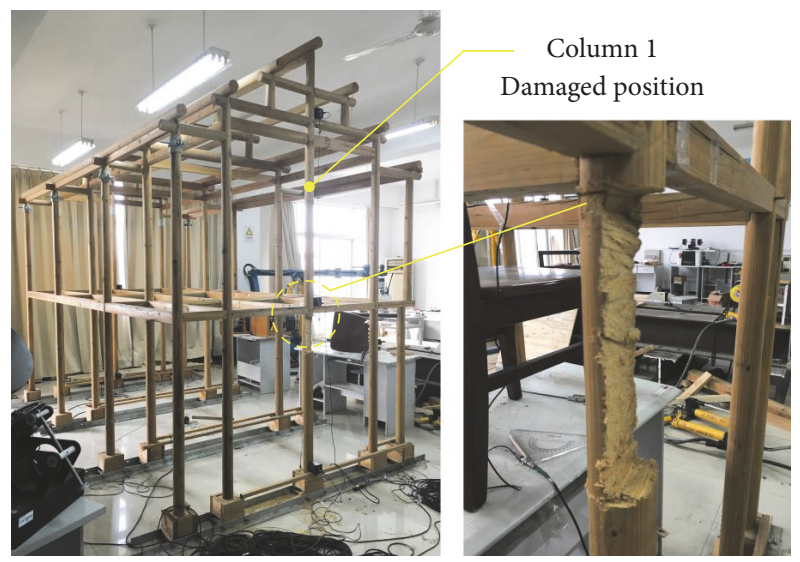

FIgURE 5: Damage condition 3 of Column 1.

where $C R(t)$ is the relative variation rate of entropy; $A(0)$ is the entropy value of the undamaged structure; and $A(t)$ is the entropy value of the structure under different conditions.

The relative variation rates of the WSSE values of the structure in the North-South and East-West directions under damage condition 1 are shown in Table 1 , the trends of the relative variation rates of the WSSE values are shown in Figure 7. 
TABLE 1: The relative variation rates of the WSSE values under damage condition 1.

\begin{tabular}{lcccccc}
\hline Points & 1 & 2 & 3 & 4 & 5 & 6 \\
\hline N-S & 0.1328 & 0.0076 & 0.0025 & 0.0208 & 0.0392 & -0.0101 \\
E-W & 0.2134 & 0.0153 & 0.0054 & 0.0026 & 0.0207 & 0.0245 \\
\hline
\end{tabular}

TABLE 2: The relative variation rates of the WSSE values under damage condition 2.

\begin{tabular}{lcccccc}
\hline Points & 1 & 2 & 3 & 4 & 5 & 6 \\
\hline N-S & 0.2083 & 0.0534 & 0.0101 & 0.1068 & 0.0588 & -0.0051 \\
E-W & 0.1979 & 0.0254 & 0.0269 & 0.1023 & 0.0388 & 0.0380 \\
\hline
\end{tabular}

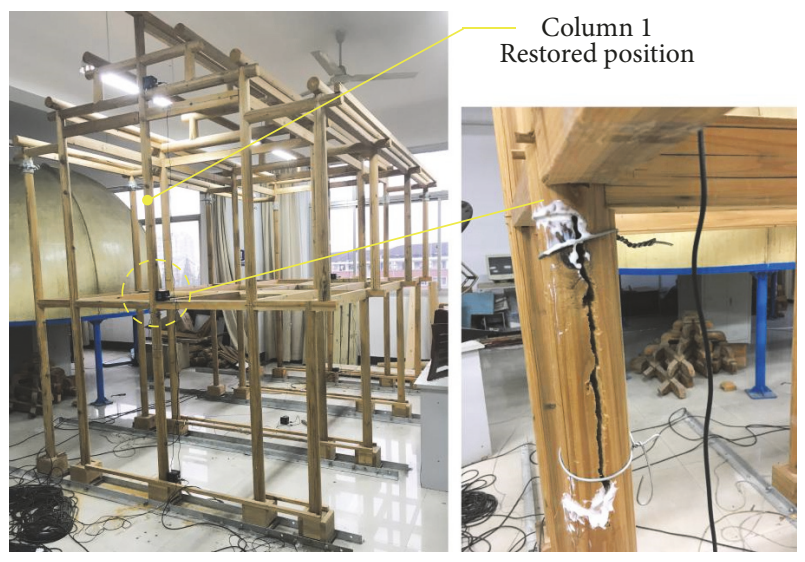

FIgURE 6: Restored condition of Column 1.

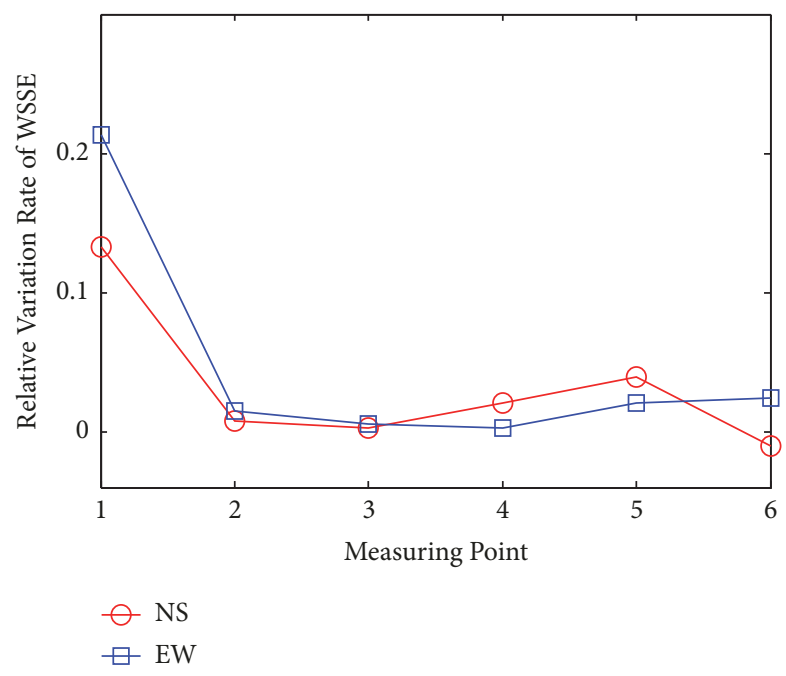

FIGURE 7: Relative variation rate of WSSE under damage condition 1.

It can be seen from Figure 7 that the relative variation rates of WSSE in both the North-South and East-West directions of point 1 are higher than those of other measured points. Corresponding to reality, point 1 is located in the column base that is corroded completely.

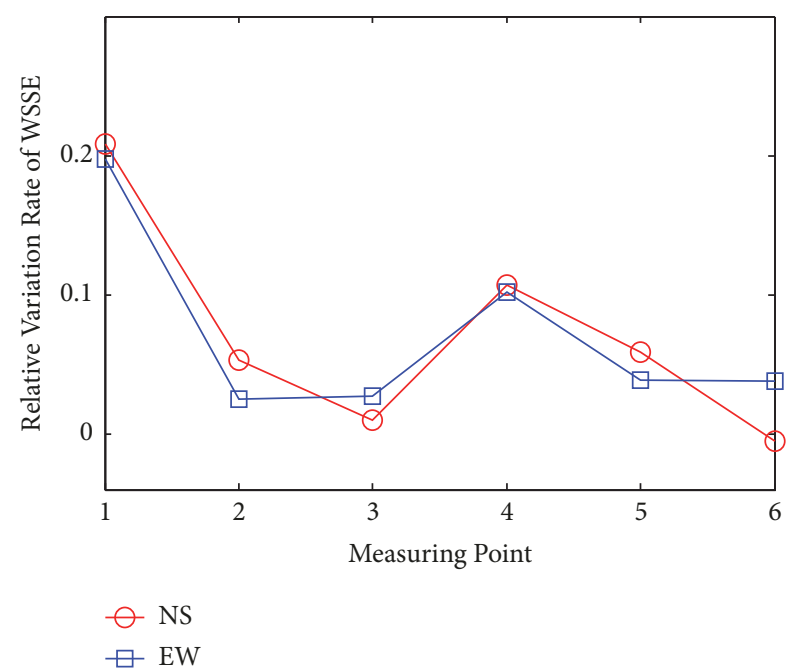

FIGURE 8: Relative variation rate of WSSE under damage condition 2 .

The relative variation rates of WSSE in the North-South and East-West directions under damage condition 2 are shown in Table 2, and the trends of the relative variation rates of the WSSE values are shown in Figure 8.

It can be seen from Figure 8 that the relative variation rates of WSSE of measured points 1 and 4 in the NorthSouth and East-West directions are higher than those of other points. Points 1 and 4 are located at the bottom of the first floor of Column 1 and Column 2. Therefore, the results derived from WSSE are identical to the actual damaged situation.

The relative variation rates of WSSE corresponding to damaged Column 1 in the North-South and East-West directions under damage condition 3 are shown in Table 3 , and the trends of the relative variation rates of the WSSE values are shown in Figure 9.

The variation rates of WSSE of measured point 2 in the North-South and East-West directions are higher than those of other measured points (Figure 9). Point 2 corresponds to the node of the second floor of Column 1. Therefore, the results determined by WSSE are consistent with the actual condition.

The change in WSSE for the restored structure and the values of WSSE in the North-South and East-West directions 
TABLE 3: The relative variation rates of the WSSE values under damage condition 3.

\begin{tabular}{lccccrr}
\hline Points & 1 & 2 & 3 & 4 & 5 & 6 \\
\hline N-S & -0.0026 & 0.0814 & -0.0050 & 0.0078 & 0.0319 & 0.0000 \\
E-W & 0.0051 & 0.0280 & 0.0134 & 0.0205 & 0.0181 & 0.0217 \\
\hline
\end{tabular}

TABLE 4: The relative variation rates of the WSSE values under restored condition of damage condition 3.

\begin{tabular}{lccccrr}
\hline Points & 1 & 2 & 3 & 4 & 5 & 6 \\
\hline N-S & 0.0026 & 0.0025 & 0.0126 & -0.0078 & 0.0025 & 0.0127 \\
E-W & -0.0180 & 0.0153 & 0.0081 & -0.0077 & 0.0207 & 0.0190 \\
\hline
\end{tabular}

TABLE 5: Elastic characteristics of fir wood.

\begin{tabular}{lccccccr}
\hline $\mathrm{G}_{\mathrm{RT}}$ & $\mathrm{G}_{\mathrm{LR}}$ & $\mathrm{G}_{\mathrm{LT}}$ & $\mathrm{E}_{\mathrm{L}}$ & $\mathrm{E}_{\mathrm{T}}$ & $\mathrm{E}_{\mathrm{R}}$ & $\mu_{\mathrm{RT}}$ & $\mu_{\mathrm{LR}}$ \\
\hline 217.3 & 905.3 & 724.2 & 12070 & 1207 & 603.5 & 0.68 & 0.42 \\
\hline
\end{tabular}

Note. The unit of elastic modulus is MPa. L: longitudinal direction; R: radial direction; T: tangential direction; RT: cross section; LR: radial section; LT: tangential section.

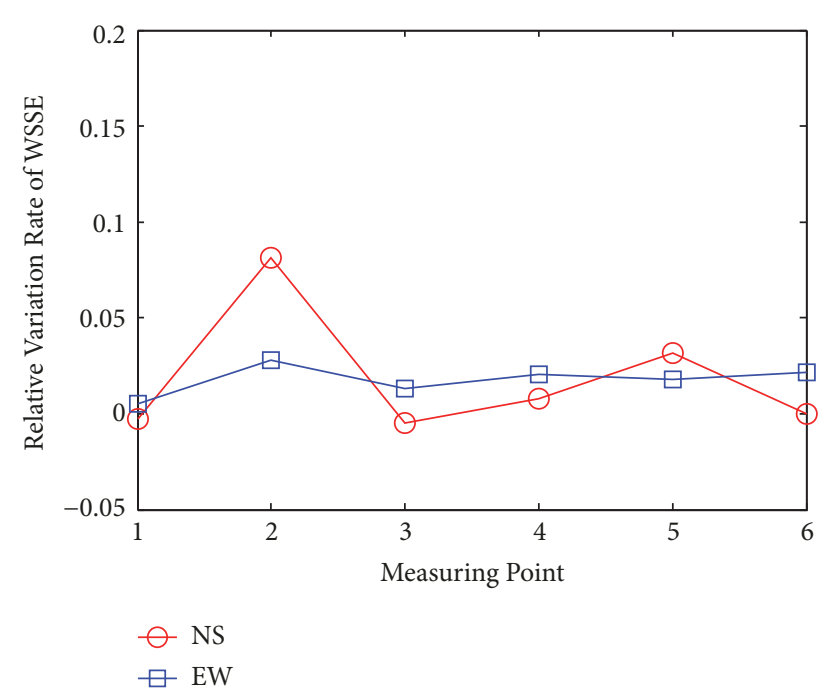

FIGURE 9: Relative variation rate of WSSE under damage condition 3.

are analyzed and shown in Table 4. The comparison of relative variation rates of WSSE of the damaged and restored structures is shown in Figure 10.

From Figure 10, we can see that the relative variation rates of WSEE at measuring point 2 in the North-South and East-West directions decrease after restoration. According to the methods proposed above, the reduction in relative variation rate is due to the reduction in the degree of damage after restoration. In addition, the feasibility of this restoring method is demonstrated. The results of this research indicate that using the variation rate of WSSE is effective in identifying the location of damage of a structure.

\section{Numerical Analysis}

4.1. Damage Simulation of Timber Structure. To simulate the damage to the timber structure, the finite element method is used. Beam 188 unit [13], elastic unit [14], and SOLID186 unit [15] are used to simulate the semirigid node of the mortise and tenon joint, beam-column member, and damaged semicylinder, respectively. To consider the characteristics of fir wood, the column is compressed and the beam is curved along the grain. The elastic characteristics of the various sections of wood are listed in Table 5 [16]. The mass of the roof and wall is not considered in the calculation. In the actual structure, the column is put into the grooved stone base, which cannot limit the rotation of the column completely. Therefore, a fixed hinge support is chosen in the simulation to be consistent with the actual situation [17]. The finite element model of the timber structure developed in this study is shown in Figure 11.

In this study, based on ANSYS software, the model is analyzed by transient dynamic theory, and the white noise signal is used as input to simulate the conditions of natural environment excitation of the model. To obtain the acceleration response signal of the corresponding measured points of the structure, the value of wavelet singular spectrum entropy is calculated by using a MATLAB program.

The simulated damaged condition in the finite element model corresponds to the test model. The damage conditions are shown in Table 6.

4.2. Damage Identification. Damage condition 1 and condition 2 are taken as examples to show the effectiveness of using the relative rate of WSSE as an indicator to determine the location of damage. The relative rates of WSSE for damage condition 1 obtained from the numerical method are shown in Tables 7 and 8. The comparison of the relative rates of WSSE for damage condition 1 and damage condition 2 obtained from the model test and numerical method is shown in Figure 12.

In Figure 12(a), the simulation curves with the relative variation rate of WSSE fit better with the curves in the model test both in the N-S and E-W direction. It can be indicated from these curves that there exists damage at measuring point 1, which corresponds to the bottom of Column 1, while the 
TABLE 6: The damaged and restored conditions of the timber structure.

\begin{tabular}{|c|c|c|}
\hline Condition & Damaged and restored position & Damaged or restored conditions \\
\hline 1 & Bottom of Column 1 & The bottom of Column 1 is completely corroded. \\
\hline 2 & Bottom of Column 1 and Column 2 & $\begin{array}{c}\text { The bottom of both Column } 1 \text { and Column } 2 \text { are } \\
\text { completely corroded. }\end{array}$ \\
\hline 3 & Underneath the joint of the second floor of Column 1 & The node of second floor \\
\hline 4 & Underneath the joint of the second floor of Column 1 & $\begin{array}{l}\text { The damage of Column } 1 \text { under the node of second } \\
\text { floor is restored }\end{array}$ \\
\hline
\end{tabular}

TABLE 7: The relative variation rates of the WSSE values under damage condition 1 (numerical analysis).

\begin{tabular}{lccccrr}
\hline Points & 1 & 2 & 3 & 4 & 5 & 6 \\
\hline N-S & 0.1842 & 0.0819 & 0.0937 & 0.036 & 0.0062 & 0.0761 \\
E-W & 0.1353 & -0.0054 & 0.0106 & -0.0413 & -0.0186 & 0.0187 \\
\hline
\end{tabular}

TABLE 8: The relative variation rates of the WSSE values under damage condition 2 (numerical analysis).

\begin{tabular}{lcccccc}
\hline Points & 1 & 2 & 3 & 4 & 5 & 6 \\
\hline N-S & 0.1217 & 0.0304 & 0.0363 & 0.1071 & 0.0105 & 0.0621 \\
E-W & 0.1328 & -0.0114 & 0.0037 & 0.1312 & -0.0423 & 0.016 \\
\hline
\end{tabular}

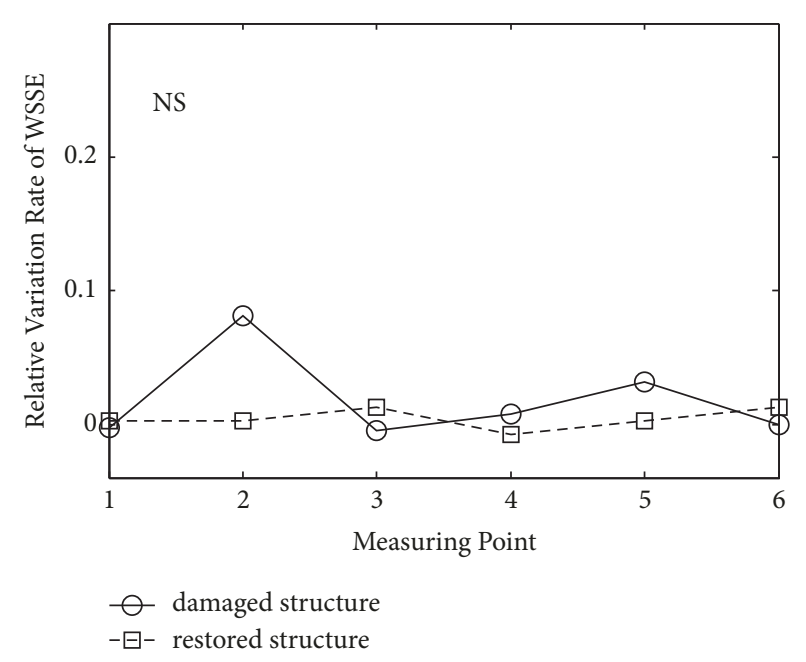

(a) North-South direction

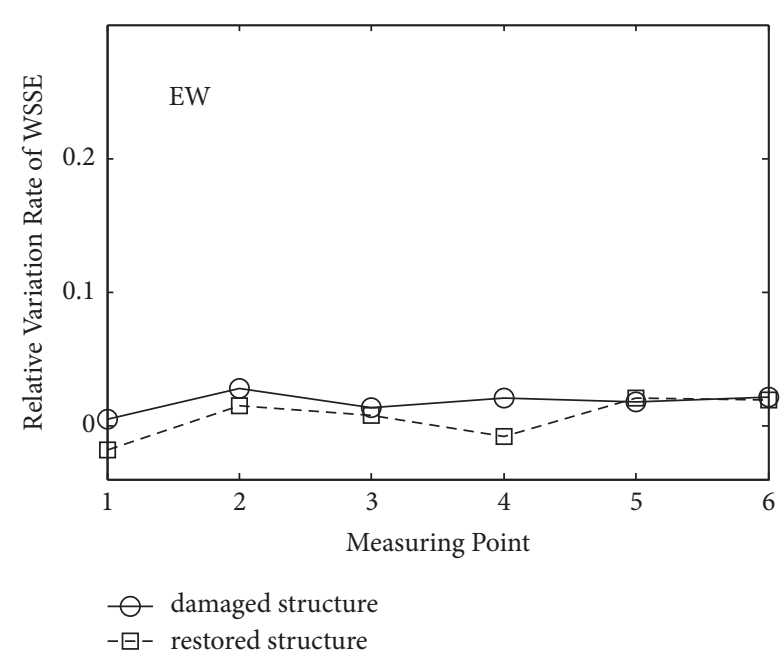

(b) East-West direction

FIGURE 10: Relative variation rate of WSSE of restored Column 1.

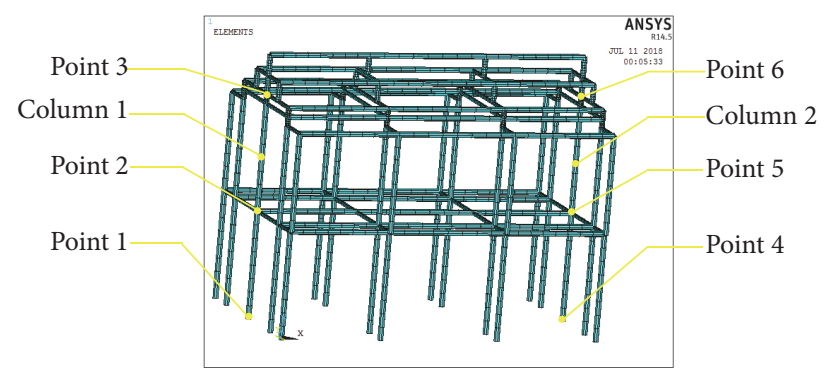

FIGURE 11: Finite element model of undamaged timber structure. 


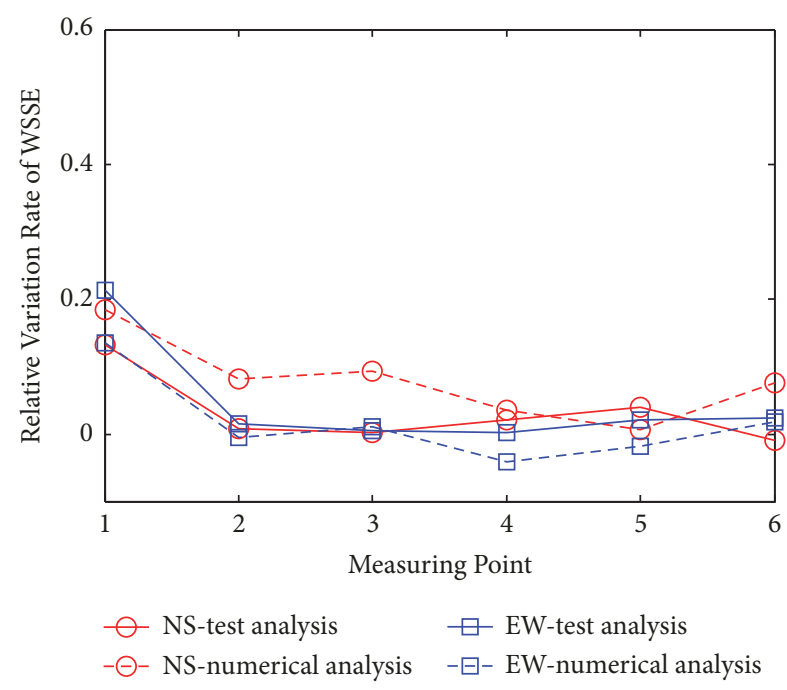

(a) Under damaged condition 1

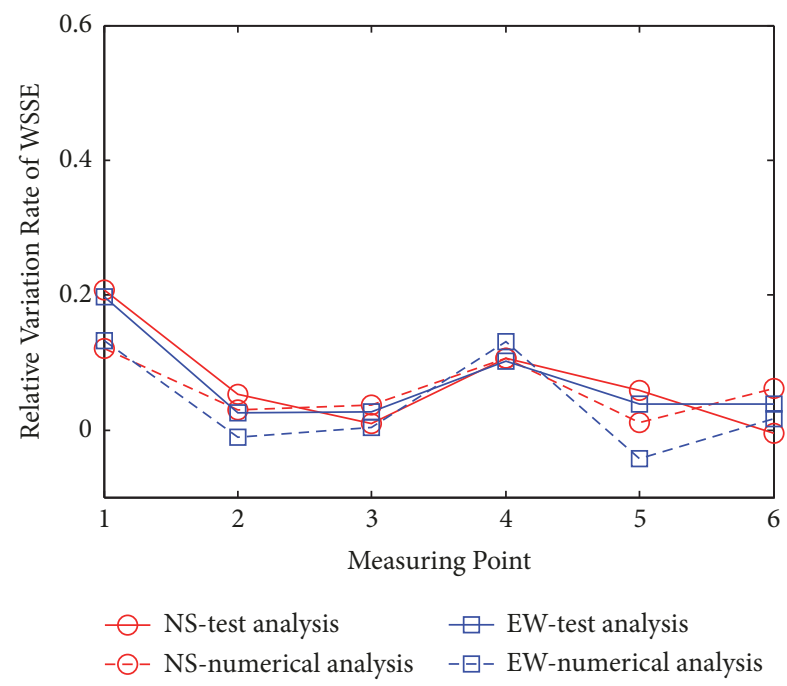

(b) Under damaged condition 2

FIGURE 12: Comparison of relative variation rates of WSSE value of the structure.

data distributions plotted in Figure 12(b) indicate that the damage occurs in point 1 and point 4 , which corresponds to damaged condition 2 in Table 6 . From the above, the results show good agreement with the real damage condition of the structure.

\section{Analysis and Discussion}

According to the analysis described above, for each damage point, the results of the finite element simulation are in good accordance with the measured data. Damage could change the value of entropy at the corresponding location; the location at which the relative variation rate of WSSE is higher indicates that this position is damaged more seriously.

Wang et al. [9] proposed a new approach to identify damage to timber structure based on wavelet packet energy curvature difference. Compared with the WSSE method proposed in this study, the wavelet packet energy curvature approach serves to decompose the high frequency part by using high frequency differential resolution. However, this method is sensitive to noise; therefore, it can accurately determine the location of damage under noiseless environment. Li [8] performed damage analysis of timber structures under random excitation using energy ratio deviation and energy ratio variance as warning indicators to reflect changes among different frequency bands. Furthermore, multiscale damage identification requires multiscale feature acquisition, which requires higher requirements for observation and measurement.

To identify the location of damage of the structure, a method based on singular spectrum entropy and impulse response was proposed by $\mathrm{Li}$ et al. [10]. The method for damage localization and determining the degree of damage using the relative variation rate of wavelet packet energy entropy was also proposed by He et al. [11]. Different from the above, this study proposes using WSSE for damage identification. The relative variation rate of WSSE is used as the characteristic parameter for damage identification, which is independent of a mathematical model, convenient, and sensitive to damage. Hence, the method proposed in this study can offer reference for detection of defects and research of timber structure.

\section{Conclusions}

In this study, a method to inspect the location of damage in a timber structure is proposed by using the relative variation rate of WSSE as an indicator. The effectiveness of the method proposed in this study is verified through experimental test and numerical simulation of the timber structure. The conclusions are as follows:

(i) The relative variation rate of WSSE changes considerably at the location of damage. The relative variation rate of WSSE is higher in the position that has been damaged more seriously.

(ii) The value of WSSE is sensitive to damage of the timber structure, even for a minor damage. When the damage is preliminary identified as slight, the number of survey points needs to be increased.

(iii) The values of entropy in the North-South and EastWest directions are different. Thus, the signals in the two directions are required for further identification.

The effectiveness of this method is verified through a model test and numerical analysis, which lays a theoretical foundation for study on damage identification of the timber structure under environmental excitation.

\section{Data Availability}

The data used to support the findings of this study are available from the corresponding author upon request. 


\section{Conflicts of Interest}

The authors declare that there are no conflicts of interest regarding the publication of this paper.

\section{Acknowledgments}

This paper is supported by the National Natural Science Foundation of China (Grant No. 51478409, 51338001), the State Administration of Foreign Experts Affair (Grant No. GDT20183200375), and Program of 100 Foreign Experts in Jiangsu Province (Grant No. JSB2017029).

\section{References}

[1] R. O. Curadelli, J. D. Riera, D. Ambrosini, and M. G. Amani, "Damage detection by means of structural damping identification," Engineering Structures, vol. 30, no. 12, pp. 3497-3504, 2008.

[2] P. S. Addison, The illustrated wavelet transform handbook, introductory theory and application in science, engineering, medicine and finance, CRC Press, Boca Raton, FL, USA, 2nd edition, 2017.

[3] M. Rucka and K. Wilde, "Application of continuous wavelet transform in vibration based damage detection method for beams and plates," Journal of Sound and Vibration, vol. 297, no. 3-5, pp. 536-550, 2006.

[4] D. Hester and A. González, "A wavelet-based damage detection algorithm based on bridge acceleration response to a vehicle," Mechanical Systems and Signal Processing, vol. 28, pp. 145-166, 2012.

[5] E. Douka, S. Loutridis, and A. Trochidis, "Crack identification in beams using wavelet analysis," International Journal of Solids and Structures, vol. 40, no. 13-14, pp. 3557-3569, 2003.

[6] L. H. Yam, Y. J. Yan, and J. S. Jiang, "Vibration-based damage detection for composite structures using wavelet transform and neural network identification," Composite Structures, vol. 60, no. 4, pp. 403-412, 2003.

[7] Q. Wang and X. Deng, "Damage detection with spatial wavelets," International Journal of Solids and Structures, vol. 36, no. 23, pp. 3443-3468, 1999.

[8] X. F. Li, The multi-scale damage analysis for ancient architecture timber structure based on wavelet transforms, [M.Sc. thesis], Xi'an University of Architecture and Technology, Xi'an, Shaanxi, China, 2013.

[9] X. Wang, W. B. Hu, and Z. B. Meng, "Damage detection of an ancient wood structure based on wavelet packet energy curvature difference," Journal of Vibration and Shock, vol. 33, no. 7, pp. 153-159, 2014.

[10] R. Li, D. J. Yu, and W. Zeng, "Damage diagnosis of structures based on singular spectrum entropy and impulse response," Journal of Vibration Engineering, vol. 19, no. 3, pp. 331-335, 2006.

[11] C. He, J. Xing, J. Li, W. Qian, and X. Zhang, "A new structural damage identification method based on wavelet packet energy entropy of impulse response," The Open Civil Engineering Journal, vol. 9, no. 1, pp. 571-577, 2015.

[12] S. H. Mahdavi and H. Abdul Razak, "A Comparative Study on Optimal Structural Dynamics Using Wavelet Functions," Mathematical Problems in Engineering, vol. 2015, Article ID 956793, 10 pages, 2015.

[13] ANSYS Theory Manual, ANSYS Version 12.0., inc., U.S.A.
[14] H. Nassiraei, M. A. Lotfollahi-Yaghin, and H. Ahmadi, "Static strength of offshore tubular T/Y-joints reinforced with collar plate subjected to tensile brace loading," Thin-Walled Structures, vol. 103, pp. 141-156, 2016.

[15] J. Y. Xue, Z. J. Wu, F. L. Zhang, and H. T. Zhao, "Seismic damage evaluation model of Chinese ancient timber buildings," Advances in Structural Engineering, vol. 18, no. 10, pp. 1671-1683, 2015.

[16] J. L. Yuan and Y. Yang, Rectification on leaning timber structure frame with traditional composite tools, Science Press, Beijing, China, 2017.

[17] Z. B. Meng, J. Yuan, M. Z. Wu, W. B. Hu, and K. Zhang, "The influence of high-station base of ancient building on its seismic responses," Journal of Xian University of Architecture Technology, vol. 40, no. 6, pp. 835-840, 2008. 


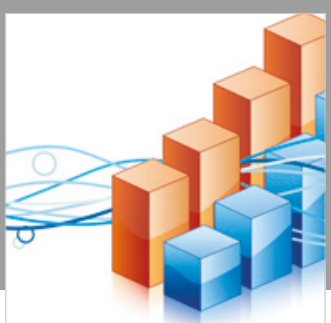

Advances in

Operations Research

\section{-n-m}
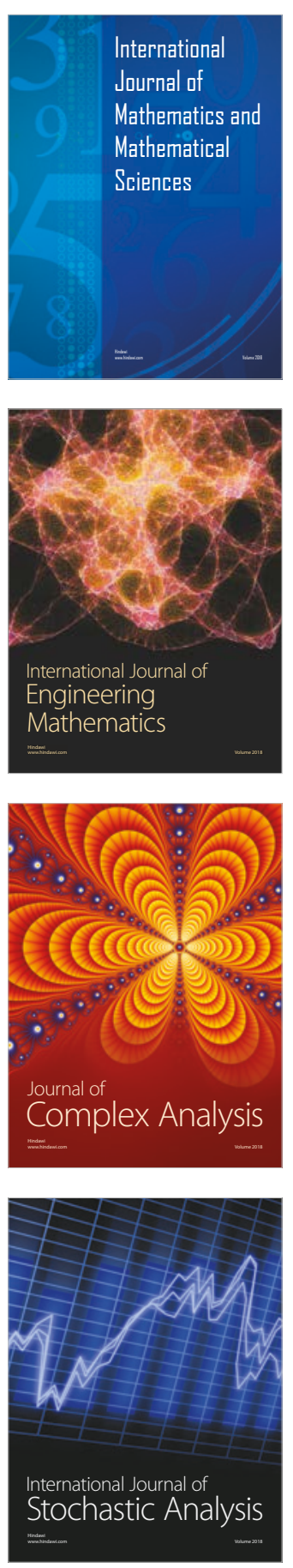
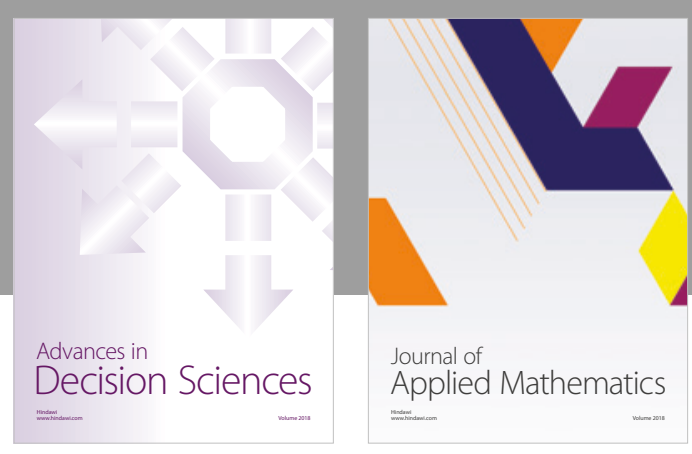

Journal of

Applied Mathematics
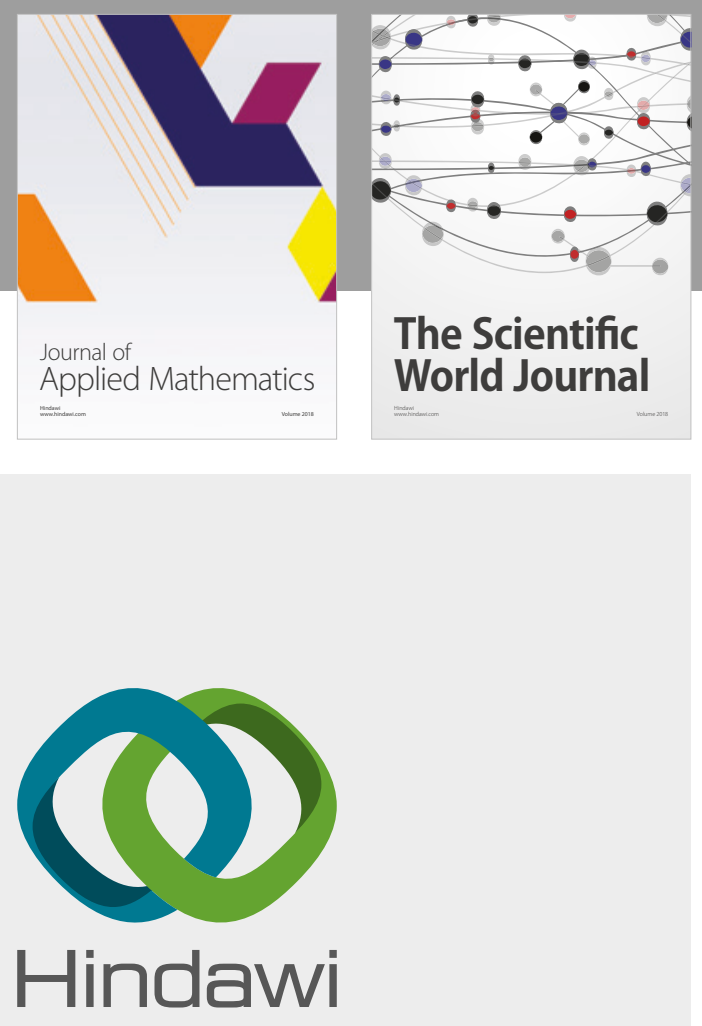

Submit your manuscripts at

www.hindawi.com

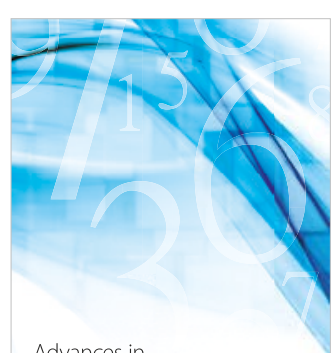

Advances in
Numerical Analysis
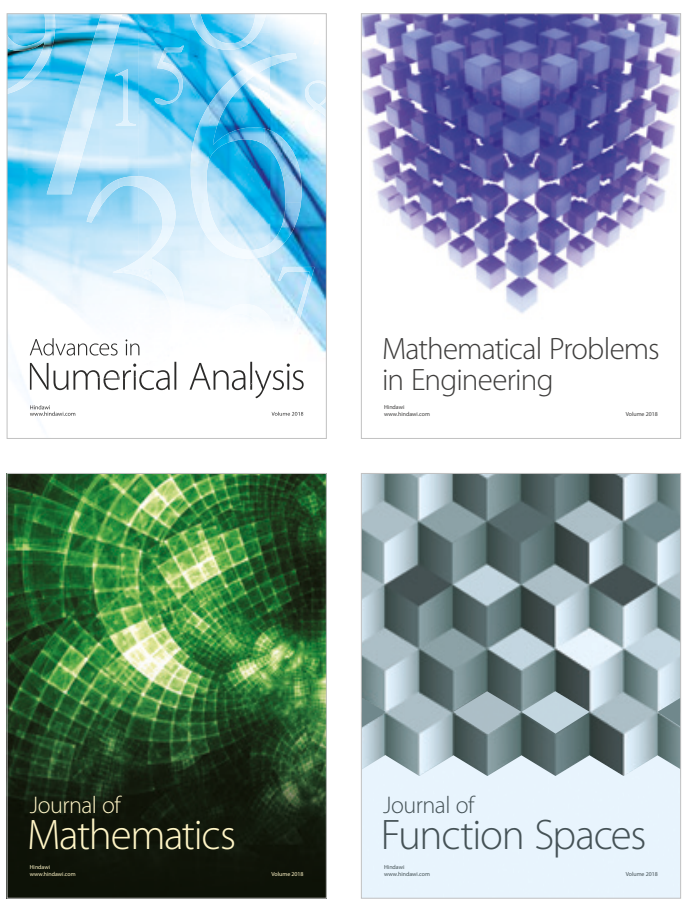

Mathematical Problems in Engineering

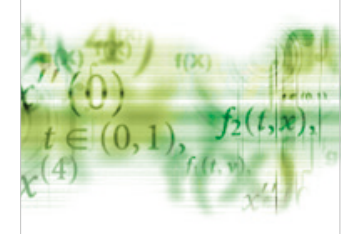

International Journal of

Differential Equations

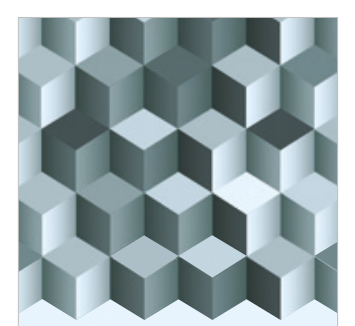

Journal of

Function Spaces

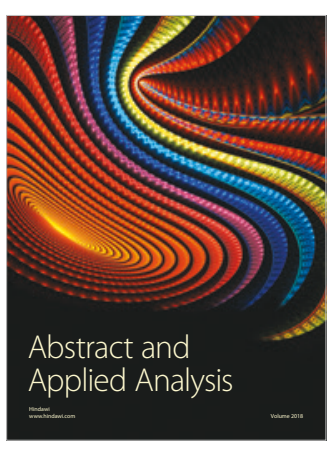

The Scientific

World Journal

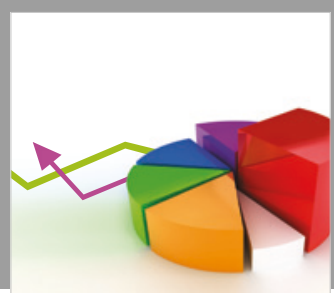

Journal of

Probability and Statistics
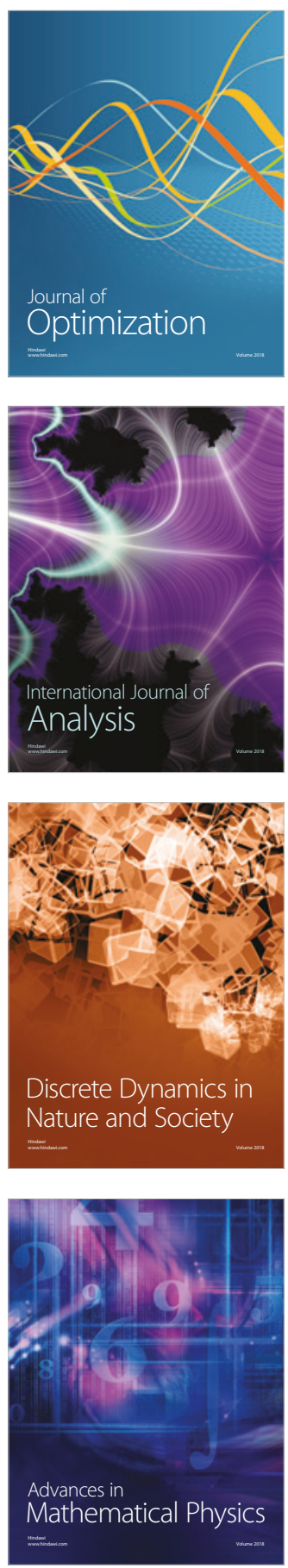